PRINCÍPIO DE FUNCIONAMENTO DO MOTOR ELÉTRICO UNIVERSAL: REFLEXÃO EDUCACIONAL A PARTIR DE EXPLICAÇÕES DE UMA VERSÃO DIDÁTICA TIPO SÉRIE ${ }^{+*}$

\author{
Osmar Henrique Moura da Silva \\ Alexandre Urbano \\ Carlos Eduardo Laburú \\ Departamento de Física - UEL \\ Londrina $-\mathrm{PR}$
}

\begin{abstract}
Resumo
É comum a divulgação de determinada versão simples e de baixo custo do motor elétrico tipo série (ou universal) para fins pedagógicos que pode ser muito proveitosa. No entanto, devido à sua geometria e disposição das bobinas, percebe-se uma dificuldade para se determinar as direções e os sentidos das forças responsáveis pelo torque no rotor, originando explicações inadequadas ou incompletas do seu princípio de funcionamento. Essa dificuldade se faz presente em divulgações a respeito desse motor sendo ainda corroborada por revelações de uma amostra de professores investigada que se dedicou a estudar o experimento. Considerando isso, este estudo contribui para melhor aclarar a origem do movimento rotacional do rotor da versão didática do motor em série aqui apresentada na medida em que fica ajustada corretamente a aplicação das forças magnéticas ali envolvidas. Finaliza-se com uma reflexão que conscientiza acerca do cuidado educacional a respei-
\end{abstract}

\footnotetext{
Working principle of universal electric motor: educational reflection from an explanation of version type teaching series

* Recebido: novembro de 2012. Aceito: março de 2013.
} 
to das explicações fisicicas do funcionamento dos motores elétricos em geral.

Palavras-chave: Motor elétrico universal (tipo série). Ensino. Princípio de funcionamento.

\begin{abstract}
It is common the disclosure of a simple and low-cost version of an electric motor type series (or universal) for pedagogical purposes that can be quite profitable. However, due to their geometry and the arrangement of the coils, it is noticed a difficulty in determining the directions and the senses of the forces responsible for the rotor torque, resulting in incomplete or inadequate explanations for their operating principle. This difficulty is present in disclosures about this engine being further supported by revelations of investigated sample teachers who dedicated to study the experiment. Considering that, this study contributes to better clarify the origin of the rotational movement of the rotor didactic version of this engine in series adjusted by application of magnetic forces involved there. It ends with a reflection that raises awareness about the educational care about the physical explanations of the operation of electric motors in general.
\end{abstract}

Keywords: Universal electric motor (type series). Teaching. Operation Principle.

\title{
I. Introdução
}

Este trabalho insere-se em uma linha de publicações deste periódico (LANG; AXT, 2003; SILVA; LABURÚ, 2004), cujas contribuições baseiam-se no fornecimento de correções de explicações inadequadas, ou às vezes simplificadas em demasia, que com frequência têm sido realizadas com determinados fenômenos. Dentro dessa perspectiva, o presente estudo chama a atenção para uma versão simples e de custo reduzido do motor elétrico em série (ou universal), que é bem 
divulgada para a utilidade didática ${ }^{1}$. No entanto, embora potencialmente proveitosa para esse fim, sua geometria e disposição das bobinas (nos estatores e rotor) parecem dificultar uma aplicação válida do entendimento baseado na "equação da força ao solenóide" (OREAR, 1971, p. 193) para explicar a origem do giro do rotor, logo, do princípio físico de seu funcionamento. Isso porque é corriqueira uma explicação simplista na qual o movimento ocorre pela ação recíproca entre campos magnéticos, em que se concebe uma força originária pela interação entre os campos magnéticos dos estatores e o do rotor . Esta explicação possivelmente tem sido proliferada a partir de muitos, inclusive educadores, que igualmente pecam por uso de uma conduta instrucional simplista a determinados níveis de ensino e que compromete o esclarecimento do funcionamento dos motores em série comercializados ${ }^{3}$. A corroborar esta preocupação, revelações de uma amostra de professores de um curso de especialização em física para o Ensino Médio, dedicado a estudar o funcionamento do motor didático em foco, fortalecem a indicação de que tal explicação é geralmente feita neste caso aparentemente mais complicado.

É sabido que não poucas explicações são realizadas no cotidiano de forma simplificada ou equivocada e que até se justificam por serem de mais fácil adaptação em determinada comunicação sem prejudicá-la, como ocorre, por exemplo, com o conceito de calor já bem divulgado na literatura (SILVA et al., 2008). Todavia, sendo esta conduta indesejada em situações educacionais em que as devidas aplicações de um termo, lei ou teoria, são exigidas, o presente trabalho objetiva esclarecer o princípio físico do funcionamento da referida versão didática do motor elétrico em série, enfatizando reflexões que alertam para se evitar as explicações simplistas que se aparentam propensas a ocorrer nesse contexto.

\section{A versão didática do motor elétrico tipo série}

A versão didática de baixo custo do motor elétrico do tipo série pode ser elaborada de duas formas, ambas diferenciadas apenas no que se refere à adaptação do comutador. Em uma delas, o comutador permite que o circuito seja fechado, havendo passagem de corrente elétrica no rotor quando este se encontra em posi-

\footnotetext{
$1<\mathrm{http}$ //www.feiradeciencias.com.br/sala22/Motor06.asp $>$

$2<$ http://www.feiradeciencias.com.br/sala22/Motor06.asp $>$

3 Exemplo: <http://pt.scribd.com/doc/3969812/Aula-04-Acionamento-de-Motores-Eletricos>
} 
ção horizontal, enquanto na outra forma, isso ocorre com o rotor em posição vertical. Para esta última, os detalhes de montagem encontram-se divulgados no site mencionado na nota de rodapé 1 . Abaixo, aborda-se a outra forma, cuja disposição do comutador é planejada para acionar o rotor na horizontal.

O motor é constituído de um rotor centralizado entre dois estatores. O rotor pode ser arquitetado com arame de clipes de 1,5 $\mathrm{mm}$ de diâmetro e fio de cobre esmaltado no 21 AWG. Já para cada estator, tem-se o mesmo fio enrolado em um prego de $6 \mathrm{~cm}$ de comprimento e $5 \mathrm{~mm}$ de diâmetro. A quantidade de espiras do rotor é em número de vinte (20) e está especificada na Fig. 1, que ainda permite observações dos sentidos dos enrolamentos, sendo isto melhor detalhado na Fig. 6 (A e B) mais adiante. No lado esquerdo da Fig. 1, têm-se as dimensões do rotor. Nela podem ser notados dois pequenos rolinhos de fita crepe adaptados ao eixo para evitar que ele gire sem cair dos mancais. Os estatores são eletroímãs, sendo cada um deles composto por duas camadas de enrolamentos envolvendo um núcleo de prego, totalizando aproximadamente 100 espiras (detalhe na imagem do lado direito da Fig. 1). Há uma ligação em série dos estatores com o rotor, em que cerca de 6 V são suficientes para a demonstração do seu funcionamento. As extremidades do enrolamento do rotor são lixadas para o contato físico no comutador (contatos verticais) durante as rotações, abrindo e fechando o circuito.

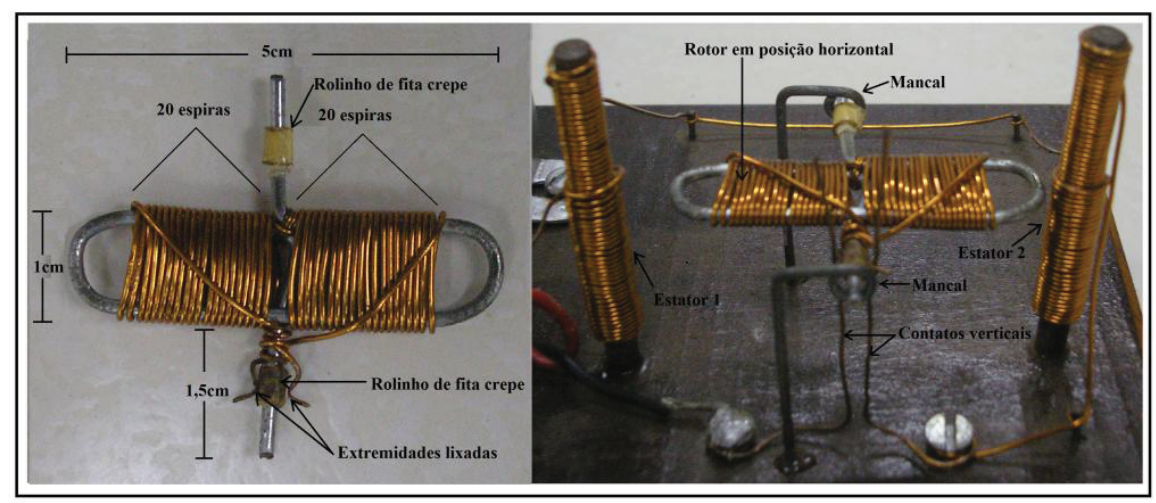

Fig. 1 - Imagem detalhada do rotor e de sua acomodação horizontal entre os estatores.

\footnotetext{
${ }^{4}$ Retirando o verniz isolante.
} 
Ainda na Fig. 1, nota-se que o comutador (contatos verticais) somente aciona o rotor se ele estiver na horizontal, ou com um pequeno ângulo além dela, enquanto houver o contato físico para a passagem de corrente elétrica. Fora disso, como na posição vertical, ele opera por inércia. Na imagem direita da Fig. 1, temse o motor adaptado em uma base, em que é possível perceber a orientação do enrolamento do fio de cobre nos eletroímãs (estatores), de modo que os sentidos dos campos magnéticos gerados são sempre equivalentes, tanto no caso de corrente contínua como na alternada. Os mancais, feitos com o mesmo arame de clipes do rotor, são curvados na medida apropriada para um livre giro do eixo e na altura centralizada do rotor entre os estatores.

\section{A explicação incorreta}

Os ímãs são objetos interessantíssimos e muito conhecidos no cotidiano. Todos percebem a atração que existe entre dois polos magnéticos norte e sul quando estão próximos, e a repulsão, entre polos iguais. A analogia que existe entre bobinas com corrente contínua e ímãs, entendendo-os como dipolos magnéticos, induz, no caso da versão do motor deste trabalho, uma explicação inadequada para seu princípio de funcionamento. Pode-se dizer que essa versão apresenta um problema desafiador para aqueles que baseiam seu entendimento na equação da força magnética, mais apropriada a qualquer configuração análoga a um segmento com corrente elétrica sob campo magnético, com o objetivo de caracterizar as forças que provocam o torque do rotor.

O presente estudo constatou que todos os treze professores de Física, estudantes de um curso de especialização em Física para o novo ensino médio da instituição em que se encontram os autores, forneceram explicações para a rotação, tendo dificuldades em aplicar o adequado entendimento físico sem esclarecer corretamente o fenômeno. A explicação mais comum fornecida, e que estes professores realizaram, simplesmente baseia-se na interação do campo magnético do rotor com o campo magnético dos estatores e que, de uma reunião dos comentários dos professores investigados, os raciocínios podem ser assim sintetizados: "as forças que originam o movimento ocorrem por atração numa extremidade do rotor $e$ repulsão na outra, em razão da interação entre os campos magnéticos do rotor e dos estatores". Coerentemente com isso, a Fig. 2 apresenta os desenhos explicativos divulgados em um popular site que apresenta essa versão didática do motor em série e que destaca essa visão errônea para o seu princípio de funcionamento. Os desenhos retratam fases de funcionamento da versão didática deste motor em série, ilustrando a interação campo/campo. No caso da Fig. 2, a única diferença com a 
daquela que se discutiu na seção anterior é a posição do comutador (traços na horizontal), que assim aciona o rotor quando na vertical.

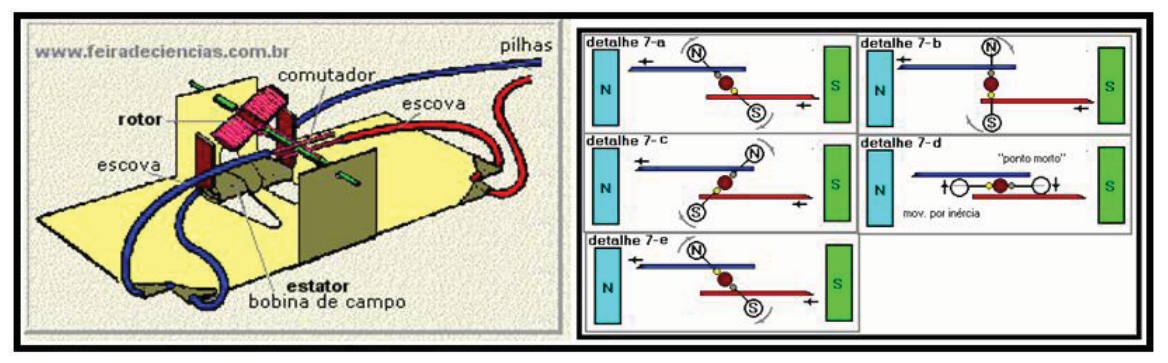

Fig. 2 - No lado esquerdo pode-se observar que o comutador possui os contatos dispostos na horizontal, diferentemente do apresentado na última seção. No lado direito estão os desenhos explicativos. Site:

$<$ http://www.feiradeciencias.com.br/sala22/Motor06.asp $>$.

A comprovar ainda mais o argumento do uso frequente desse inconveniente entendimento, ilustra-se parte de uma apostila (divulgada na internet ${ }^{5}$ ), elaborada de um conceituado curso de graduação em engenharia elétrica de uma universidade federal, destinada ao estudo do acionamento do motor elétrico em série comercializado. Admiravelmente, lá podem ser vistos comentários como o de que "campos magnéticos de mesma polaridade se repelem e campos magnéticos de polaridade diferente se atraem", referindo-se ao desenho de eletroímãs da Fig. 3(A). Para os desenhos da Fig. 3(B) que trata da parte móvel do motor (rotor) explica-se que, "em função da polaridade, os campos magnéticos submetem o rotor a forças de atração e repulsão, produzindo o movimento giratório do rotor"; reafirmando que este entendimento não é incomum.

\section{A explicação correta}

O princípio físico de funcionamento de motores elétricos abrange duas expressões classicamente conhecidas dos livros de física básica:

$$
\begin{gathered}
\boldsymbol{F}_{\text {(mag.) }}=\mathrm{I} \boldsymbol{l} \times \boldsymbol{B} \\
\boldsymbol{\tau}=\mathrm{I} \boldsymbol{S} \times \boldsymbol{B}
\end{gathered}
$$

${ }^{5}$ Site: $<$ http://pt.scribd.com/doc/3969812/Aula-04-Acionamento-de-Motores-Eletricos>. 


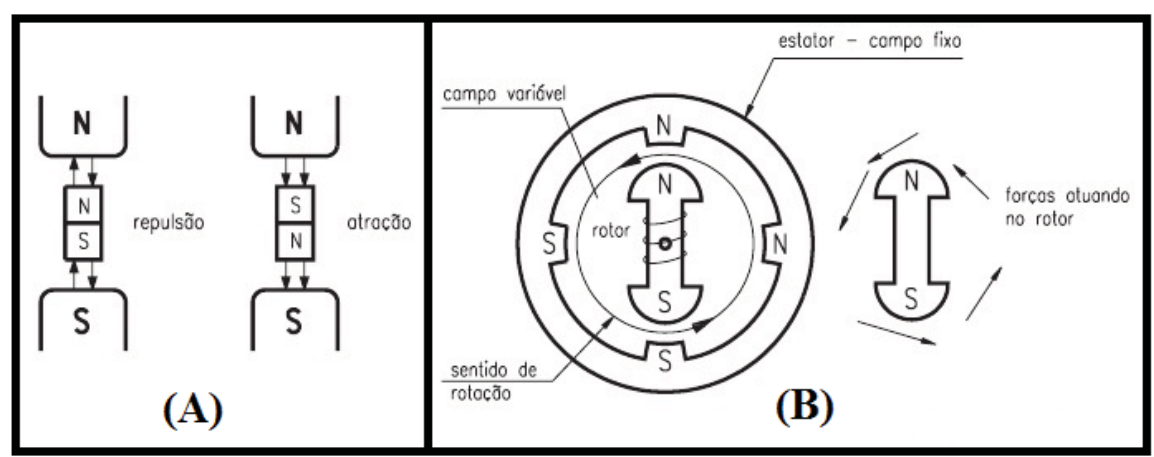

Fig. 3 - Diagramas esquemático explicativos. Site:

$<$ http://pt.scribd.com/doc/3969812/Aula-04-Acionamento-de-MotoresEletricos >.

A primeira trata-se da força magnética que age sobre um segmento qualquer de fio condutor em que passa uma corrente elétrica. A segunda trata do efeito dessa força, relacionando-a com o torque em torno de um eixo. Pela expressão (1), é apropriado usar-se da regra da mão esquerda (SEARS; ZEMANSKY, 1967, p. 673) para determinar a direção da força sobre o condutor no campo magnético (ibid., p. 686), obtendo a resultante da somatória das forças nos segmentos condutores (neste caso, aproximadamente retilíneos) do rotor do motor elétrico (ibid., p. 699). A aplicação dessa regra é vista na Fig. 4, onde, para maiores esclarecimentos, se faz essa regra na espira central do rotor (Fig. 4(E)), cuja posição desenhada deste rotor equivale à da pequena foto atrelada no canto superior direito. Na Fig. 4(E), a espira retangular considerada transporta uma corrente I e encontra-se no campo magnético uniforme $\boldsymbol{B}$ dos estatores, conhecidamente mapeado com limalhas de ferro. A regra da mão esquerda aplicada ao segmento condutor superior da espira central na Fig. 4(E) nos dá uma força $\boldsymbol{F}_{1}$ perpendicular ao campo de sentido para a esquerda e com módulo obtido pela expressão (1). Para o segmento inferior, o módulo da força $\left(F_{2}\right)$ é o mesmo, mas com sentido oposto. Embora a força magnética resultante seja zero em relação ao centro de massa, tanto pelas forças laterais

6

No pequeno desenho da mão esquerda ao lado, a regra é originalmente aplicada a uma partícula em movimento, mas é igualmente válida ao se basear em termos da corrente I e de um deslocamento $l$ (expressão 1), vetor este cuja direção é a mesma que a da velocidade vetorial de arraste dos portadores positivos de carga.

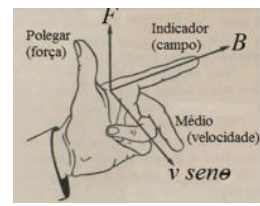


como pelas forças superior $\left(F_{1}\right)$ e inferior $\left(F_{2}\right)$ explicadas, estas duas últimas geram torques no eixo do rotor. Na Fig. 4(D), a distância perpendicular do eixo à linha de ação dessas duas forças é $r\left({ }_{\perp}\right)=(1 / 2) w \operatorname{sen} \theta$, em que os módulos dos torques relativos são: $\tau_{1}=(1 / 2) w F_{1} \operatorname{sen} \theta$ e $\tau_{2}=(1 / 2) w F_{2} \operatorname{sen} \theta$.

Os torques têm rotações com sentidos anti-horários nas figuras, em que a Fig. 4(C) ilustra o pequeno ângulo limite de atuações suficientes para impulsionar o rotor, situação limite esta em que o binário de forças anula-se diametralmente ao eixo, além de se considerar não haver corrente elétrica por tal posição do rotor já não ter contato com o comutador. É importante observar que as dimensões da espira são $l$ e $w$, de modo que a área do plano da espira é $S=l w$. Por conveniência, pode-se usar o vetor de área $S$ para especificar a orientação do anel, conforme ilustrado na Fig. 4(D), tendo-se apresentado direção perpendicular ao plano da espira com sentido determinado pela regra da mão direita (KELLER et al., 1999, p. 180). Logo, o torque magnético resultante tem módulo $\tau=\tau_{1}+\tau_{2}=w \mathrm{I} l B \operatorname{sen} \theta=$ ISBsen $\theta$.

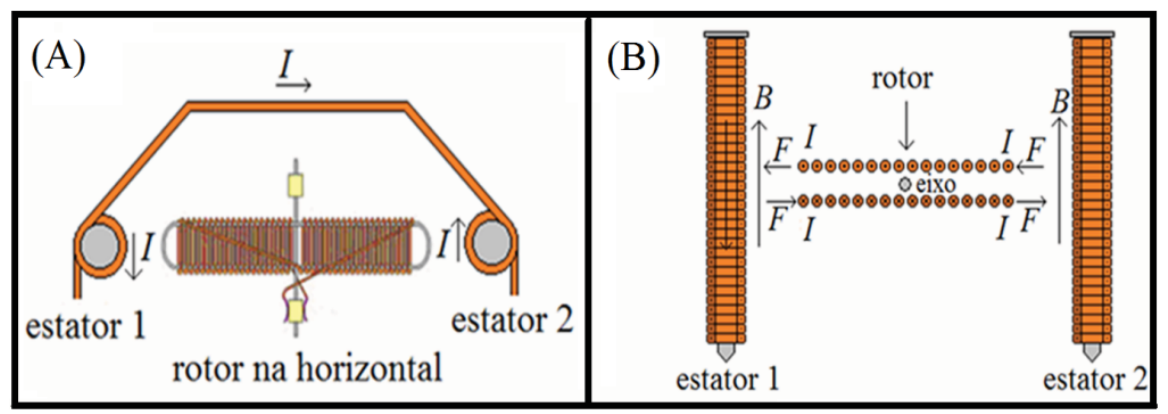

Fig. 4 - A) Vista por cima com sentido da corrente elétrica nos estatores tendo o rotor na horizontal; B) Vista lateral do motor com o rotor na horizonta ${ }^{8}$;

\footnotetext{
${ }^{7}$ Dedos da mão direita dobrados para acompanhar o sentido da corrente ao longo do circuito com polegar distendido indicando a direção de $S$.

${ }^{8}$ Pelas convenções da Física, pequenos círculos com pontos representam correntes com direção perpendicular ao plano do papel, com sentido saindo deste. Já os círculos marcados com cruz representam correntes com mesma direção e sentido oposto. Algumas observações devem ser feitas: 1) Note que, se o rotor girar meia volta na horizontal, a disposição inicial de seus enrolamentos com os terminais de contato (comutador) permanece a mesma; 2) Independente do sentido da corrente elétrica, pois pode-se usar a corrente contínua ou alternada, os sentidos apresentados do binário de forças magnéticas explicado permanecem sempre os mesmos. Isso ocorre porque ao inverter a corrente elétrica no circuito e, assim, na
} 


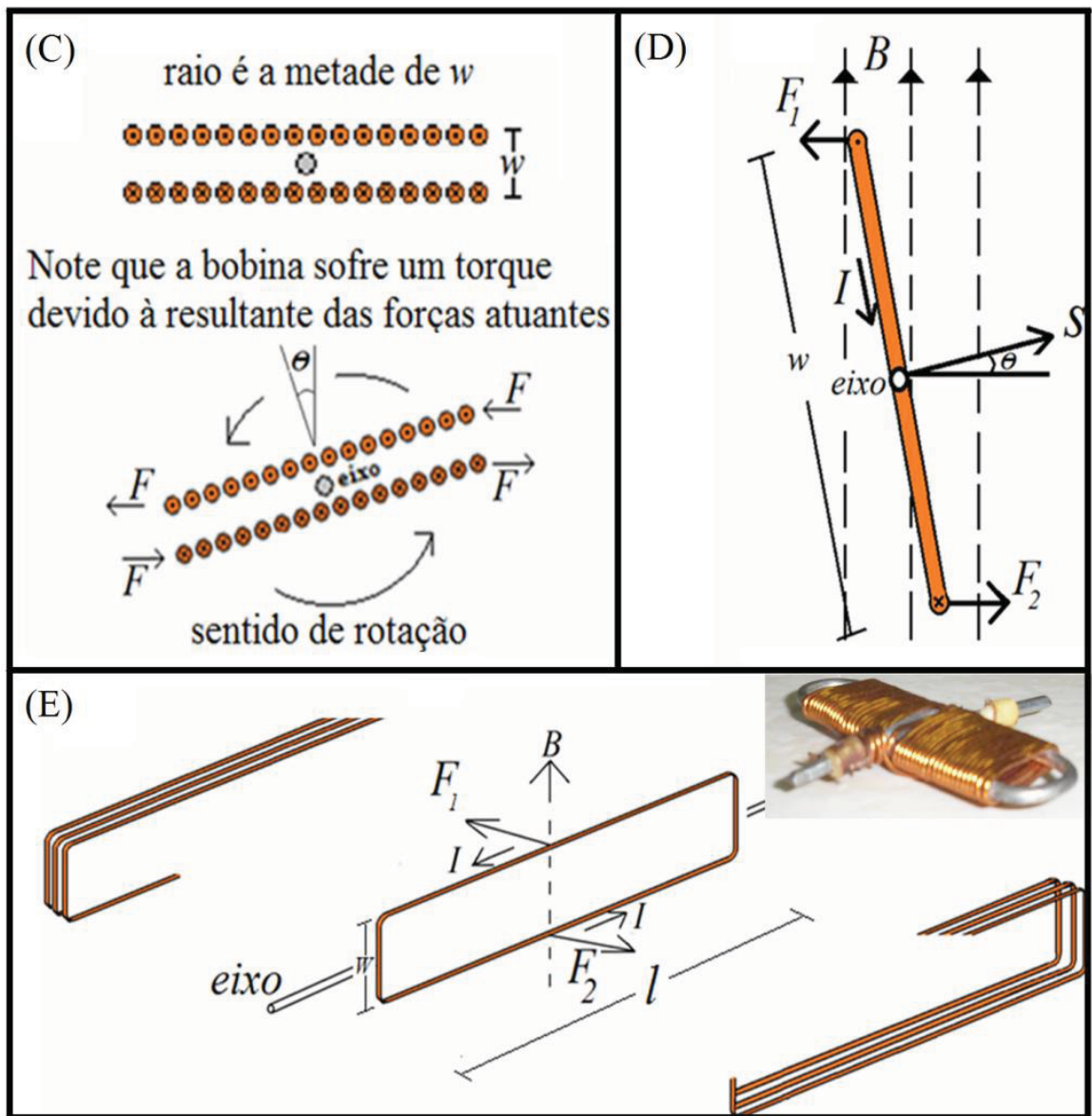

Continuação Fig. 4: C) Ilustração do ângulo limite de atuação das forças que geram o torque magnético; D) Torque de sentido de rotação anti-horário com indicação do vetor S; E) Aplicação da regra da mão esquerda na espira central com disposição da bobina equivalente à pequena foto em canto superior direito.

Esta é a expressão 2 que, no arranjo da Fig. 4(D), tem o sentido da rotação do torque anti-horário, assim como o sentido de rotação que levaria a direção do

bobina móvel, invertem-se os polos magnéticos dos estatores. Portanto, o fato de a corrente ser alternada não provoca mudança no sentido do torque. 
vetor área $\boldsymbol{S}$ à direção de $\boldsymbol{B}$ por um ângulo $\theta$, dando-se o torque total sobre a bobina com $\mathrm{N}$ espiras ${ }^{9}$ igual a: $\boldsymbol{\tau}=\mathrm{NIS} \times \boldsymbol{B}$.

Portanto, sinteticamente e de forma qualitativa, dada pelas expressões $1 \mathrm{e}$ 2, o giro do rotor ocorre em razão do torque provocado por forças de origem magnética, resultantes da interação entre os campos magnéticos criados pela corrente elétrica nos enrolamentos dos estatores e esta mesma corrente, que também circula pelo enrolamento do rotor. Essas forças magnéticas que atuam sobre as espiras do enrolamento do rotor têm direções e sentidos que podem ser determinados pela regra da mão esquerda (GREF, 1993, p. 139).

\section{Reflexões conceituais relacionadas}

O funcionamento de todo motor elétrico universal, independentemente da maneira como são ligados o rotor e as bobinas de campo (estatores) ${ }^{10}$, se dá por corrente contínua ${ }^{11}$, sendo aí as analogias entre bobinas de corrente contínua e ímãs bem apreciadas. Na prática, é habitual falar-se em polos norte e sul de uma bobina. Todavia, vale esclarecer que tal linguagem é figurada, pois, de acordo com o Eletromagnetismo, uma bobina não pode ter polos. Há apenas a simulação da existência de polos em razão de uma grande concentração das linhas de campo que fazem com que nas extremidades os efeitos magnéticos se intensifiquem (assim como para os ímãs). Em termos de correntes elétricas, a analogia com os ímãs acontece na medida em que o campo magnético gerado por eles se deve à existência dessas correntes no interior do material magnético, associadas aos movimentos dos elétrons dos átomos cujo efeito global equivale a uma corrente sobre a superfície do material que constitui o ímã, permitindo-se pensar que o campo magnético do ímã é produzido por essa corrente em sua superfície. Logo, nesse sentido, o ímã é análogo à bobina, pois ambos geram campos magnéticos devido a correntes elétricas. (GREF, 1993).

\footnotetext{
${ }^{9}$ Transportando corrente I em um campo magnético.

1) Série; 2) Paralelo ou shunt; 3) Compound. (ZEARS; ZEMANSKY, 1967, p. 699).

${ }^{11}$ Ou alternada, já explicada, que, aliás, por ser a padronizada nas redes elétricas, é mais usualmente utilizada nesses motores. Motores universais, devido ao elevado torque que apresentam em baixa rotação, são utilizados em liquidificadores, aspiradores de pó, furadeiras, entre outros.
} 
Para a interação entre bobinas ${ }^{12}$ nas quais circulam correntes elétricas e, em particular, para o caso do motor universal, isso não se deve, conceitualmente, à ação do campo magnético de uma delas sobre o campo da outra. Em termos de princípios físicos, tais campos somente mediam a interação entre correntes ${ }^{13}$. Conforme GREF (ibid., p. 121), tal interação é bem compreendida se: "primeiro, pensarmos que a corrente em uma das bobinas cria um campo magnético e, segundo, que a corrente elétrica da outra é capaz de 'sentir' o campo criado pela primeira ${ }^{14}$. Assim, a interação bobina-bobina é entendida como uma interação correntecorrente ${ }^{15}$ ". Dentro de uma visão clássica, campos magnéticos, como quaisquer campos, se somam vetorialmente, segundo o princípio da superposição (SEARS et al., 1984, p. 671) originando um campo final. Um campo não repele ou atrai outro campo, mas se superpõem compondo um campo resultante. Assim, forças são produzidas devido à ação de campos sobre partículas ou correntes, como no caso estudado. Deste modo, as práticas regras das mãos direita e esquerda são úteis para a compreensão do funcionamento dos motores elétricos, bem como muitos aparelhos de medida, dada a orientação: 'corrente 'cria' um campo, corrente 'sente' um campo, mas um campo não 'sente' outro campo" (GREF, p. 125). Por meio desse entendimento, o diagrama da Fig. 5 equivale ao da Fig. 3B e serve de comparação entre o que foi explanado na terceira seção e a forma como o presente entendimento mostra-se agora aplicado ao funcionamento de um típico motor elétrico universal.

Há uma ressalva explicativa a ser feita para o entendimento a respeito do momento de dipolo magnético $(\boldsymbol{m})$ e que nos desenhos da terceira seção aparentam apenas faltar uma seta entre as polaridades para se desconfiar que lá fora pensado; apesar de todos os professores citados e investigados nada referirem sobre esse conceito propriamente dito. $\mathrm{O}$ conceito de momento de dipolo magnético fica bem

\footnotetext{
12

Ou mesmo no caso dos ímãs.

OREAR (1971, ps. 191-195) faz uma seção do seu livro cujo propósito "é explicar a maneira como os ímãs se comportam, puramente em função das forças entre correntes".

14

"As equações de Maxwell mostram como as cargas produzem campos; reciprocamente, a lei da força mostra como os campos afetam as cargas" (GRIFFITHS, 2011, p. 227). 15

Ressalta Griffiths (ibid.) que a noção de que campos elétricos podem ser produzidos por cargas ou por variação dos campos magnéticos e os campos magnéticos podem ser produzidos por correntes ou por variação dos campos elétricos "é, na realidade, um tanto enganosa". Isto porque, encarando os fatos, variações de campos magnéticos ou elétricos "são em si decorrentes de cargas e correntes" (ibid.).
} 


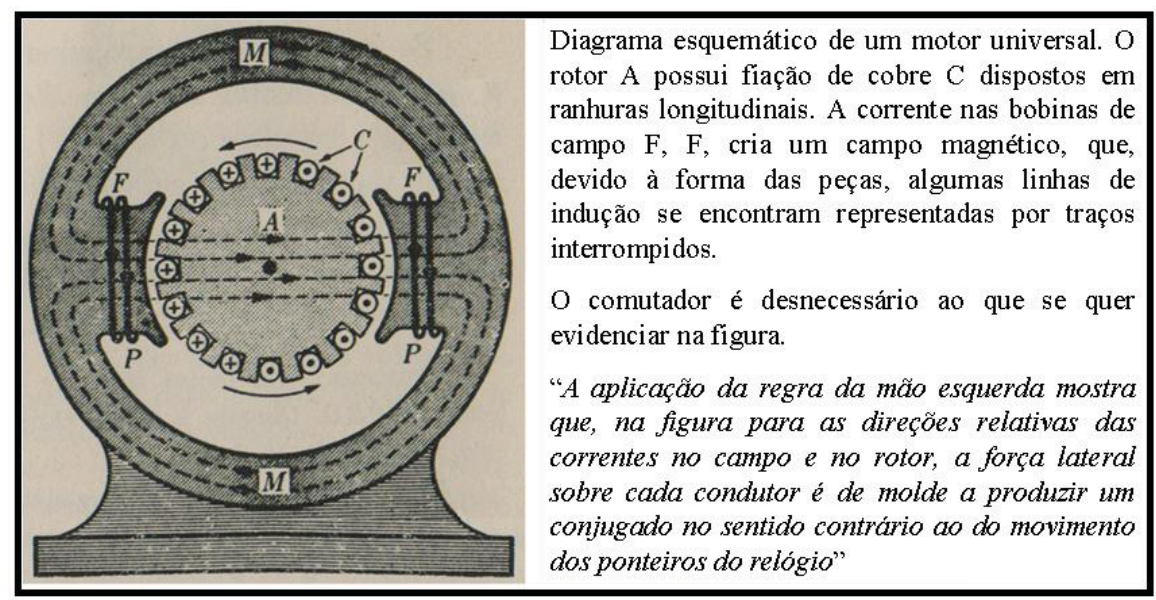

Fig. 5 - Desenho e comentários em Sears e Zemansky (1967, p. 699).

apropriado a magnetos em barra (ímãs) por seus comportamentos em campos magnéticos e que, por analogia, até se pode qualificá-lo como uma bobina móvel (rotor) transportadora de corrente. No entanto, tal semelhança de comportamento não deve legitimar o uso desse conceito na situação aqui focada, conforme alertam Sears \& Zemanky (1967, p. 689): “O comportamento de uma barra imantada é usualmente explicado, atribuindo o conjugado sobre ela, exercido pelas forças magnéticas produzidas sobre 'polos' situados em suas extremidades. Vemos, entretanto, que tal interpretação não é necessária no caso de um solenoide." Por esse entendimento, Orear (1971, p. 193) diz que, "de fato, um solenoide, quando colocado em um campo magnético externo tende a se alinhar com o campo da mesma maneira que uma barra magnetizada", mas isso só "pode verificar-se aplicando a equação da força (expressão 1) ao solenoide" onde a regra da mão esquerda "diznos que a força sobre a parte inferior da uma espira é dirigida para baixo e a força sobre a parte superior é para cima". E sintetiza: "É este conjugado que é o princípio (de funcionamento) do motor elétrico" (ibid.).

Com essas reflexões pretende-se que um maior cuidado seja dado quanto às explicações do movimento rotacional causado por um torque em um motor elétrico, levando em conta a advertência de Keller et al. (1999, p. 180-181): “o leitor deve (grifo dos autores) aplicar a equação (equação 1) às configurações análogas (a uma espira de corrente)". 


\section{Considerações finais}

No cotidiano escolar, explicações simplificadas ou mesmo equivocadas são utilizadas em razão de convenientemente se adaptarem a determinadas situações, sem prejuízo de contradizer os fatos. Para o caso da interação entre ímãs ou eletroímãs, em geral, o entendimento pelo qual se analisam unicamente suas polaridades para explicar forças atrativas e repulsivas observadas pode ser apropriada ao nível fundamental de ensino e útil no dia-a-dia. Entretanto, em níveis educacionais mais elevados, em que a disciplina de Física se insere ao conteúdo programático do curso, é preciso fazer um refinamento da linguagem para a cientificamente correta. Este estudo apontou como educadores de níveis médio e universitário podem se descuidar, nesse sentido, quando explicam o funcionamento de motores elétricos universais, em especial a versão didática aqui abordada. Diante disso, forneceu-se aqui um esclarecimento do movimento rotacional do rotor pela aplicação da equação da força magnética a essa versão discutida, enfatizando reflexões que pretendem contribuir para que educadores de Física e interessados em geral possam mais facilmente evitar a explicação ingênua que aqui se procurou alertar ${ }^{16}$.

\section{Referências}

GREF. Física 3: Eletromagnetismo. Edusp: São Paulo, 1993.

GRIFFITHS, D. J. Eletrodinâmica. 3. ed. Pearson Education do Brasil Ltda.: São Paulo, 2011.

GOMES, D. Eletricidade: acionamento de motores elétricos. Disponível em: $<$ http://pt.scribd.com/doc/3969812/Aula-04-Acionamento-de-Motores-Eletricos>. Acesso em: 19 set. 2012.

KELlER, F. J.; GETTYS, W. E.; SKOVE, M. J. Física. Makron Books do Brasil Editora Ltda: São Paulo, 1999. v. 2.

\footnotetext{
${ }^{16}$ Faz-se aqui um agradecimento póstumo ao Professor Luiz Ferraz Netto (In Memorian) que, por meio de seu popular site, divulga um valoroso trabalho que continuamente desenvolvia, destinado a ajudar todos aqueles comprometidos com atividades experimentais para feira de ciências.
} 
LANG, F. S.; AXT, R. Explicação qualitativa para o 'anel de Thompson': como ocorre a 'levitação magnética'? Revista Brasileira de Ensino de Física, v. 25, n. 1, p. 81-85, mar. 2003.

NETTO, L. F. Feira de Ciências - o imperdível. Disponível em: $<$ http://www.feiradeciencias.com.br/sala22/Motor06.asp $>$. Acesso em: 19 set. 2012.

OREAR, J. Física. Livros Técnicos e Científicos Editora Ltda: Rio de Janeiro, 1971.

SEARS, F. W.; ZEMANSKY, M. W. Física. Sedegra Sociedade Editora e Gráfica Ltda: Rio de Janeiro, 1967.

SEARS, F. W.; ZEMANSKY, M. W.; YOUNG, H. D. Física 3 - Eletricidade e Magnetismo. 2. ed. Livros Técnicos e Científicos Editora S.A.: Rio de Janeiro, 1984.

SILVA, O. H. M; LABURÚ, C. E. Invisibilidade da garrafa (a explicação correta). Caderno Brasileiro de Ensino de Física, v. 21, n. 1, p. 111-114, abr. 2004.

SILVA, O. H. M; LABURÚ, C. E.; NARDI, R. Reflexões para subsidiar discussões sobre o conceito de calor em sala de aula. Caderno Brasileiro de Ensino de Física, v. 25, n. 3, 2008. 